\title{
ESTRATÉGIAS EMPREENDEDORAS EM ENFERMAGEM
}

\section{Silvana Dias Leão'; Bethânia Kraemer Haag²; Elviani Santos Stefano3; Regina Celia de Castro Gomes ${ }^{4}$; Mara Caino Teixeira Marchiori ${ }^{5}$; Dirce Stein Backes ${ }^{6}$;}

\section{RESUMO}

Objetivou-se conhecer as potencialidades e as fragilidades encontradas, por Enfermeiros, no protagonismo de ações/empreendimentos empreendedores.

Metodologia: Pesquisa exploratório-descritiva, de abordagem qualitativa, realizada entre março e agosto de 2018, com 11 enfermeiros de cinco estados brasileiros, com reconhecida atuação empreendedora na área de Enfermagem, a partir de entrevistas individuais norteadas pela técnica Snowball. Resultados: Os dados organizados e analisados pela técnica de análise de conteúdo temática, resultaram três categorias: Potencialidades empreendedoras da enfermagem; Fragilidades encontradas no processo empreendedor e Estratégias ampliadoras de empreendedorismo na Enfermagem. Conclusão: O Enfermeiro desempenha crescente função proativa e empreendedora nos diferentes espaços de atuação profissional. Embora incipiente e com poucas evidências científicas disponíveis, o empreendedorismo da Enfermagem se destaca pelas habilidades e potencialidades agregadoras, integradoras e dinamizadoras de um novo pensar e agir profissional.

\footnotetext{
1 Silvana Dias Leão - Acadêmica de Enfermagem da Universidade Franciscana. E-mail: silvana.d.leao@gmail.com

2Bethânia Kraemer Haag - Enfermeira. Egressa do Mestrado Profissional em Saúde Materno Infantil da Universidade Franciscana. E-mail: bethaniahaag@hotmail.com

${ }^{3}$ Elviani Santos Stefano - Enfermeira. Egressa do Mestrado Acadêmico em Ciências da Saúde e da

Vida da Universidade Franciscana. E-mail: stefano.elviani@ufn.edu.br

${ }^{4}$ Regina Celia de Castro Gomes - Enfermeira. Aluna do Mestrado Profissional em Saúde Materno Infantil da Universidade Franciscana. E-mail: rcgomes123@yahoo.com.br

${ }^{5}$ Mara Caino Teixeira Marchiori - Doutora em Enfermagem. Docente do Curso de Enfermagem e Mestrado Profissional em Saúde Materno Infantil da Universidade Franciscana. E-mail: maramarc@ufn.edu.br

${ }^{6}$ Dirce Stein Backes - Doutora em Enfermagem. Docente do Curso de Enfermagem e Mestrado Profissional em Saúde Materno Infantil da Universidade Franciscana. E-mail: backesdirce@ufn.edu.br
} 
Palavras-chave: Empreendedorismo; Empreendedorismo na Enfermagem; Enfermagem

Eixo Temático: Atenção Integral e Promoção à Saúde (AIPS).

\section{INTRODUÇÃO}

O conceito de empreendedorismo vem sendo aprofundado, no Brasil, desde a década de 90, com o avanço da abertura de micro e pequenas empresas, principalmente, em decorrência dos mecanismos de globalização. A partir deste período, muitas empresas têm investido em seu potencial de diferenciação, com vistas a aumentar a competitividade e assegurar a sua permanência no mercado. Tal processo, vem ampliando as possibilidades empreendedoras, sobretudo, pela conquista de novos patamares e espaços de autonomia nas diferentes áreas do conhecimento ${ }^{(1)}$.

O empreendedorismo pode ser definido como um novo modelo de intervenção proativa no mercado, capaz de (re)criar, explorar, ousar e motivar os profissionais a encararem desafios na prática de empreendimentos rentáveis. Esse processo de intervenção autônoma vem se configurando como um mecanismo de inovação e superação das práticas tradicionais (2). Exercer o empreendedorismo, sob esse enfoque, transcende o caráter assistencialista de intervenção e/ou apenas o alcance de resultados pela estabilidade financeira (3).

$\mathrm{Na}$ área da saúde, o empreendedorismo vem ganhando espaço, portanto, pela inovação tecnológica e a geração de novos negócios. Já, na Enfermagem, as iniciativas empreendedoras vêm conquistando espaço, mais especificamente a partir da última década, com a ampliação da percepção teórica sobre o tema e dos espaços de intervenção profissional, sejam eles autônomos ou em serviços já existentes (4-5).

Estudos demonstram, que na área de enfermagem o empreendedorismo está se configurando como um novo mecanismo de intervenção social, associado às características pessoais e profissionais, como a autonomia, a independência, a flexibilidade, a inovação, a proatividade, a autoconfiança e o compromisso social. Não basta, no entanto, exercer o empreendedorismo gerando algo novo, é necessário 
desenvolver habilidades empreendedoras, no sentido de definir metas e vislumbrar novas oportunidades de investimento na área (6-7-8).

Reconhecendo a necessidade de ampliar as possibilidades empreendedoras, bem como investir na visibilidade profissional e social do Enfermeiro, o presente estudo tem como questão pesquisa: Quais as potencialidades e as fragilidades encontradas, por Enfermeiros, no protagonismo de ações/empreendimentos empreendedores? Com base no exposto, o presente estudo teve por objetivo conhecer as potencialidades e as fragilidades encontradas, por Enfermeiros, no protagonismo de ações/empreendimentos empreendedores.

\section{METODOLOGIA}

Trata-se de uma pesquisa exploratório-descritiva, de abordagem qualitativa. $\mathrm{O}$ estudo foi desenvolvido com enfermeiros que exercem e/ou já exerceram ações/empreendimentos empreendedores na área de enfermagem e que se propuseram a fazer parte do estudo em questão.

Os enfermeiros participantes do estudo foram selecionados por meio da técnica de Snowball, ou seja, de acordo com a amostra não probabilística utilizada em pesquisas sociais, na qual os participantes iniciais de um estudo indicam novos participantes que, por sua vez, indicam outros participantes e assim sucessivamente, até que seja alcançado o objetivo proposto ${ }^{(9)}$. Com base nestes critérios de seleção, participaram do estudo 11 Enfermeiros, de cinco estados brasileiros, sendo que apenas o primeiro participante foi escolhido pelos pesquisadores. Para esta escolha considerou-se o nome do profissional com influência empreendedora reconhecida em âmbito nacional.

Ressalta-se que a pesquisa teve fim de 11 participantes, pois, conforme metodologia descrita, as indicações finalizaram no décimo primeiro participante. Além disso, foram indicados apenas profissionais que obtiveram sucesso em suas carreiras profissionais e desta forma considerados empreendedores em sua área.

Os dados foram coletados entre março e agosto de 2018, por meio de entrevistas individuais com Enfermeiros com reconhecida atuação empreendedora na área de enfermagem. As entrevistas foram realizadas diretamente com o participante 
e/ou via Skype com os enfermeiros de outros estados do país, conduzidas por meio de questões norteadoras, quais sejam: Tendo em vista ter sido considerado empreendedor na área de Enfermagem, fale-me sobre as potencialidades e fragilidades encontradas no protagonismo de ações/empreendimentos empreendedores na área. O que você faria diferente caso iniciasse o seu empreendimento, hoje?

Os dados foram organizados e submetidos à análise de conteúdo temática proposta por Bardin, caracterizada em três etapas sequenciais. $\mathrm{Na}$ primeira, denominada de pré análise foi realizada uma leitura exaustiva dos dados, seguida da organização do material e formulação de hipóteses. Na segunda, efetuou-se a exploração do material, ou seja, codificou-se os dados brutos. Na terceira e última etapa, os dados foram interpretados e delimitados em eixos temáticos pela compreensão dos significados estabelecidos, conforme autor (10).

Para cumprir os critérios éticos foram atendidas as recomendações da Resolução do Conselho Nacional de Saúde (CNS) nº 466/2012, a qual prescreve a ética em pesquisa com seres humanos. O projeto foi aprovado pelo Comitê de Ética em Pesquisa sob o número 1.641.967. Para manter o anonimato dos depoentes, as falas foram identificadas pela letra "N", relativa à Enfermagem (Nursing), seguida de um numeral arábico que corresponde à ordem das falas.

\section{RESULTADOS E DISCUSSÕES}

Os dados organizados e analisados pela técnica de análise de conteúdo temática, resultam em três categorias: Potencialidades empreendedoras da enfermagem; Fragilidades encontradas no processo empreendedor e Estratégias ampliadoras do empreendedorismo na Enfermagem.

\section{Potencialidades empreendedoras da Enfermagem}

O mercado competitivo atual requer cada vez mais profissionais com perfil empreendedor, capazes de se adaptar à crescente complexidade das demandas emergentes da sociedade e aptos a identificar oportunidades ao invés de reproduzir posturas reativas e focadas em práticas tradicionais institucionalizadas. $O$ 
empreendedorismo, sob esse enfoque, faz surgir novos mecanismos de resolução dos problemas sociais, criando estratégias de inserção social, projetos sociais inovadores e ações empreendedoras autossustentáveis, principalmente, se norteadas por uma visão mais amplificada ${ }^{(10-11)}$.

A primeira potencialidade identificada pode ser nomeada "Lidando com as diferentes complexidades do dia a dia”. O profissional Enfermeiro possui em sua compreensão ampliada de cuidado, alcançar diferentes contextos e a multidimensionalidade humana. Estar próximo de pessoas com vulnerabilidades, contextos sociais diferentes, psicossociais, econômicos, diferentes cenários, diferentes abordagens, faz com que o Enfermeiro crie experiências e a maturidade para lidar com a complexidade do dia a dia.

A compreensão sistêmica de cuidado de enfermagem, possibilita a visão do todo e a apreensão das singularidades humanas. É dessa forma, que o profissional Enfermeiro consegue intervir com mecanismos de resolução de problemas e extrapolar a postura reativa caracterizada por práticas pré-estabelecidas, conforme depoimento a seguir:

A profissão já é empreendedora por si só... nos deparamos diariamente na prática com a escassez de produtos e precisamos solucionar e substituir. O empreendedorismo não foca no problema e sim na solução (N9).

Sendo assim, para lidar com as crescentes adversidades e incertezas do mercado competitivo, os profissionais enfermeiros necessitam da compreensão sistêmica e visão de mundo para identificar as demandas emergentes. O pensamento sistêmico, sob esse enfoque, permite ao profissional identificar as lacunas e intervir de forma proativa e empreendedora nas diferentes realidades. Sendo assim, é necessário que se realize o desenvolvimento de novas competências de forma estratégica, para que o modo de pensar e agir mantenha os objetivos e, consequentemente, a competitividade no mundo dos negócios ${ }^{(12) .}$ 
A Enfermagem, assim como todas as outras profissões, possui atuação relevante na equipe de saúde. Solucionar problemas, como a escassez de materiais, re(criar) melhorias de um produto já existente, visualizar as necessidades do paciente, são ações empreendedoras que fazem parte da dinâmica diária do profissional Enfermeiro.

Nessa mesma direção, o Enfermeiro foi apontado como sendo o "articulador e integrador de diferentes processos e profissionais". O gerenciamento é, também, evidenciado como uma das principais habilidades desenvolvidas e exercidas pelos Enfermeiros. É de responsabilidade deste profissional, em geral, a administração dos setores de saúde no quais está inserido. Ressalta-se, nessa relação, a visibilidade que a profissão atingiu nos últimos anos adquirindo espaço em empresas de saúde, setores públicos/privados em contextos de secretarias e coordenadorias de saúde, políticas sociais e de saúde, dentre outros.

Eu vejo que amplio a área de atuação do Enfermeiro, na medida em que posso estar inserido em diversas áreas distintas. Isso se deve muito ao espaço que conquistamos em nossa equipe, com o setor onde trabalhamos, com habilidades de liderança... (N2).

Outra potencialidade evidenciada nas falas dos participantes está relacionada à "iniciativa". Em sua formação, o Enfermeiro aprende formas criativas de construir conhecimento, bem como mediar processos educativos. Ousar no desenvolvimento de ações/empreendimentos autônomos significa, em suma, apostar no potencial empreendedor e conquistar a confiança da equipe.

Eu acredito que ser empreendedor é quando você cativa todos os membros da equipe através de ações que você mesmo criou...Como nessas capacitações ou implementações que fazemos diariamente em nosso campo de atuação (N4).

O Enfermeiro possui, portanto, importantes habilidades e potencialidades empreendedoras. É fundamental, para tanto, que ele próprio se reconheça em sua função como agente integrador e transformador de realidades em saúde. 


\section{Fragilidades encontradas no processo empreendedor}

A era de empreender configura-se como um processo lento e complexo que vem avançando durante a última década. Alguns profissionais, atualmente, encaram o empreendedorismo como uma saída/escape para a resolução de seus problemas pessoais e/ou coletivos. O fato deste processo ainda estar sendo estudado e aprofundado, norteia o pensamento que de a construção concreta e clara deste fenômeno ainda possui lacunas e necessita de maior tempo para ser esclarecida (11).

A primeira fragilidade encontrada, por Enfermeiros, no protagonismo de ações/empreendimentos empreendedores está relacionada à "percepção assistencialista e linear" do fazer tradicional. Por mais que essa visão tenha evoluído, nos últimos anos, muitas pessoas fora da área da saúde ainda consideram e reconhecem a Enfermagem apenas pela sua atuação no ambiente hospitalar e submissa a outros profissionais.

Demonstram, ainda, estudos que o profissional de enfermagem possui formação sólida para desempenhar diversas funções em âmbito social e de processos que envolvam a assistência à saúde em diversos setores. O mesmo estudo demostra, em suma, que a profissão de enfermagem cresceu em termos de nível nacional e internacional, mas perdeu espaço no campo de atuação, pelo fato de não apropriarse cientificamente de suas próprias práticas ${ }^{(13-14)}$.

Os próprios profissionais Enfermeiros, em geral, não se reconhecem como pesquisadores, empreendedores e incentivadores de novas práticas/tecnologias em saúde. Isso se deve, em parte, pelo modelo acadêmico verticalizado, no qual os profissionais foram formados para cumprir normas técnicas e atender às demandas fisiológicas dos usuários de saúde, conforme expresso a seguir:

Na minha época saímos da faculdade sabendo olhar e identificar só o que estava errado fisicamente com o paciente. Outras atribuições eram para os profissionais mais qualificados, como chamávamos na época. Não existia nada de gestão de equipe, desconhecíamos a palavra empreendedorismo (N7). 
Outra fragilidade encontrada no processo investigador está relacionada à "cultura reativa", atitude imposta pela sociedade, em geral. Ainda é mais comum encontrar profissionais com atitudes reativas ao invés de condutas proativas e prospectivas, as quais conduzem a processos mais autônomos e transformadores da realidade. As atitudes reativas conduzem, na compreensão dos participantes, a um fazer mecânico e reprodutor e, por sua vez, acrítico e desumanizado, conforme segue:

Acabamos nos tornando seres mecânicos... reproduzimos as mesmas coisas todos os dias. É como se nos acostumássemos com o que está errado pelo lazer de ficarmos na zona de conforto sempre (N1).

Uma das características marcantes de um empreendedor é a coragem de aventurar-se, conhecer o novo, de ousar e sair da zona de conforto. Alguns profissionais, no entanto, ainda paralisam diante de novos desafios e/ou novas provocações e preferem centrar-se em seu próprio mundo. A autoreferencialidade, no entanto, não favorece o despertar de novas ideias e o aproveitamento de novas oportunidades profissionais.

A "percepção fragmentada" da realidade foi, também, identificada como fragilidade no percurso empreendedor. A compreensão ampliada da realidade e a comunicação interprofissional devem ser considerados fatores fundamentais para a criação de redes efetivas e resolutivas. A percepção fragmentada da realidade e/ou do processo saúde-doença conduz a superficialidade, a linearidade e ao fazer técnico mecânico. Nessa relação, o usuário é geralmente apreendido apenas em sua dimensão biológica, sem considerar a multidimensionalidade e o contexto multifatorial dos fenômenos sociais.

\section{Estratégias ampliadoras do empreendedorismo na Enfermagem}

A análise das potencialidades e das fragilidades conduziram, também, a estratégias capazes de ampliar o potencial empreendedor da enfermagem, do ponto vista teórico e de intervenção nos diferentes cenários. 
Ser enfermeiro e empreender significa realizar coisas novas, pôr em prática ideias próprias e ousar criativamente no sentido de promover o novo. 0 empreendedor, por si só, tem a característica de assumir riscos e seu sucesso está em sua capacidade de conviver, sobreviver e aprender a administrá-los. Por mais que a enfermagem seja vista atualmente como uma profissão mais autônoma, o processo permanece lento e complexo, além de algumas fragilidades ainda serem evidenciadas (16-17).

O processo de "formação acadêmica como diferencial" aparece como estratégia e demonstra que a formação profissional tem potencial para conduzir e/ou não à prática do empreendedorismo. O processo de construção tanto pessoal quanto profissional, está relacionado ao fomento de abordagens teórico-metodológicas que conduzem a autonomia e o protagonismo do aluno, como agente de transformação.

A formação acadêmica, de acordo com os entrevistados, é o período em que o aluno desenvolve o seu referencial e a sua identidade profissional, a partir de atitudes inspiradoras advindas de seus professores. As metodologias significativas e as posturas docentes instigadoras podem/devem ser consideradas como alavancas essenciais para o fomento de atitudes empreendedoras entre os alunos. Embora se constituído em processo continuo e permanente de aprendizagem, o empreendedorismo precisa encontrar espaço de ação-reflexão durante a formação profissional acadêmica.

Outra estratégia nomeada e que influencia na prospecção de novos empreendimentos sociais está associada à "compreensão dos fenômenos sociais". Os fenômenos sociais determinam, em geral, o comportamento humano e influenciam nos diferentes modos de ser e conviver em comunidade. Assim, a compreensão ampliada e contextualizada dos fenômenos sociais possibilita o melhor aproveitamento das oportunidades empreendedoras e conduz a soluções proativas e voltadas à promoção e educação em saúde.

Por último, e não menos importante, apresenta-se a estratégia relacionada à "prática avançada e evidências científicas em Enfermagem". O ser e o fazer empreendedor em enfermagem requer, crescentemente, práticas fundamentadas em evidências científicas, no sentido de criar e sustentar novas teorias e práticas. A 
prática avançada em enfermagem, sob esse enfoque, além de otimizar recursos e sinergizar talentos, também comprova que o cuidado respaldado em evidências científicas transcende práticas assistencialistas e supera o fazer linear e pontual de conduzir os processos de enfermagem.

É preciso reconhecer que a enfermagem ao longo de sua história vem assumindo novas posturas e espaços, que transcendem o modelo tradicional e linear, nas quais o enfermeiro é constantemente visto e atribuído somente à realização de tarefas. A ruptura desse processo assistencialista, do saber realizar para o empreender com conhecimento, se configura como o interesse pela busca de novas oportunidades, isto é, pela busca de uma identidade própria e autônoma (16).

\section{CONCLUSÃO}

O Enfermeiro desempenha crescente função proativa e empreendedora nos diferentes espaços de atuação profissional. Embora incipiente e com poucas evidências científicas disponíveis, o empreendedorismo da Enfermagem se destaca pelas habilidades e potencialidades agregadoras, integradoras e dinamizadoras de um novo pensar e agir profissional.

A análise das potencialidades e das fragilidades conduziram, também, a estratégias capazes de ampliar o potencial empreendedor da enfermagem, do ponto vista teórico e de intervenção nos diferentes cenários. Destacam-se dentre as estratégias elencadas, a formação para o empreendedorismo, a percepção ampliada dos fenômenos sociais e a prática baseada em evidências científicas.

O estudo apresenta limitações relacionadas ao número limitado de entrevistados, a não abrangência de participantes de todos os estados brasileiros, além da impossibilidade econômica de realizar a entrevista presencial com todos os participantes do estudo.

\section{REFERÊNCIAS}

1. Drucker P. F. Inovação e espírito empreendedor. 4 ed. São Paulo: Pioneira, 1994. In: Patrício P.A.; Candido C.R. (Orgs). Empreendedorismo: uma perspectiva multidisciplinar. 1 ed. Rio de Janeiro: LTC, 2016. 19. 
2. Arribas C.M., et al. As multifaces do empreendedorismo na enfermagem brasileira. Santa Maria (RS): Centro universitário Franciscano; 2011.

3.Backes D.S., et al. O papel profissional do enfermeiro no Sistema Único de Saúde: da saúde comunitária à estratégia de saúde da família.Ciência \& Saúde Coletiva; v.17. n.1 pg. 223-230, 2012.

4. Oguisso T, Schmidt M.J. O exercicio da enfermagem: uma abordagem ético-legal. Rio de Janeiro (RJ): Guanabara Koogan; 2010.

5. Morais J.A. et al.Práticas de enfermagem empreendedoras e autônomas. CogitareEnferm. Out/Dez; vol.18. n.4. pg.695-70, 2013.

6. Martins M.J.R, Fernandes S.J.D. A visibilidade da enfermagem, dando voz à profissão: Revisão integrativa. Rev enferm UFPE on line., Recife, v.8. n.1.pg2422-33, jul., 2014.

7. Andrades A.C., et al. Empreendedorismo na Enfermagem: panorama das empresas no Estado de São Paulo.RevBrasEnferm. jan-fev; v.68 n.1. pg. 40-4 2015.

8. Backes D.S., et al. Atividades socialmente empreendedoras na enfermagem: Contribuições à saúde/viver saudável.Esc. Anna Nery, Rio de Janeiro, 20. n.1. pg7782, 2016.

9. Albuquerque K.M., et al. Cobertura do teste de Papanicolaou e fatores associados à nãorealização: um olhar sobre o Programa de Prevenção do Câncer do Colo do Útero em Pernambuco.Brasil Cad. Saúde Pública, Rio de Janeiro, 25 Supv. 2 p.301$309,2009$.

10. Bardin, L. Análise de conteúdo.Lisboa: Edições n.70; 2011. 20

11. Lisetchi M, Brancu L. The entrepreneurship concept as a subject of social innovation. Procedia-social. Behav. Sci. 2014 [cited 2017 Dec 28]; 124(5):87-92. Available from: doi: 10.1016/j.sbspro.2014.02.463.

12. Gomes, A.F. O Empreendedorismo como alavanca para o desenvolvimento local. Rev Eletrônica de Administração, v.4, n.2. 2015.

13. Polakiewicz R.R., et al.Potencialidades e vulnerabilidades do enfermeiro empreendedor: uma revisão integrativa. Perspectiva Online, v.11. n.3. pg 53-79, 2013. 


\section{OUFN}

14. Sharp DB, Monsivais D. Decreasing barriers for nurse practitioner social entrepreneurship. Journal of the American Association of Nurse Practitioners 2014; 26(10):562-6. doi: 10.1002/2327-6924.12126

15. Backes D.S., et al. Atividades socialmente empreendedoras na enfermagem: Contribuições à saúde/viver saudável.Esc. Anna Nery, Rio de Janeiro, 20. n.1. pg7782, 2016.

16. Martins M.J.R, Fernandes S.J.D. A visibilidade da enfermagem, dando voz à profissão: Revisão integrativa. Rev enferm UFPE on line., Recife, v.8. n.1.pg2422-33, jul., 2014. 